\title{
Velhice e violência na mídia impressa ${ }^{1}$
}

\author{
Beltrina Côrte (PUC-SP) ${ }^{2}$
}

\section{Resumo}

Como as notícias veiculadas nos jornais são tratadas? Simples informação, devendo obedecer aos princípios da objetividade, imparcialidade, neutralidade? Estas perguntas nortearam a pesquisa que analisou a cobertura da violência cometida contra o idoso na imprensa paulista. A partir de coleta de textos a respeito da velhice e envelhecimento em quatro jornais diários que circulam na cidade de São Paulo, foram selecionados aqueles correspondentes à violência. Analisaram-se 209 notícias de um total de 1980 matérias, extraídas de 736 edições, durante seis meses não consecutivos, entre 2004 e 2005. As páginas dos jornais impressos constatam o que está cristalizado como discurso sobre a violência, e têm, entre outros, papel de construtores da revisão da arena simbólica de uma sociedade que cada vez mais se vê obrigada a conviver com a longevidade humana.

Palavras-chaves: Velhice; violência; cobertura; jornais impressos; cidade.

\begin{abstract}
What is the approach given to news in newspapers? Are they taken for simple information, under principles of objectivity, impartiality, neutrality? These questions have guided a research on São Paulo's press news coverage regarding violence against the elderly. After gathering pieces related to the subject of elderness and getting old from four daily newspapers published in the city it was made a selection of the ones involving violence. 209 pieces were chosen for study from a total of 1980, taken from 736 newspapers editions, during 6 nonconsecutive months between the years of 2004 and 2005 . Newspapers pages showed what is settled as a discourse on violence. They have, among other roles, the one of building the symbolic stage of societies, each time more having to deal with the fact of human longevity.
\end{abstract}

Keywords: Elderness; violence; news coverage; newspapers, city 


\section{Imersão no tema}

No final da década de 70 aprendia-se nos cursos de comunicação do país que devíamos respirar 24 horas o jornalismo, comer 24 horas o jornalismo, dormir 24 horas o jornalismo... Então, achando que a vida estava além do jornalismo, resolvi sair de terras brasileiras e percorrer a América Latina a fim de sentir a vida. Respirar outros ares. Viver. Parei na Colômbia e lá estudei planejamento urbano, especialização e mestrado ao lado de colegas de diversas áreas de formação e de diferentes países. Conheci muitas pessoas, outras culturas, outras línguas. Depois trabalhei com planejamento participativo em uma região periférica de Bogotá. Lá, pela primeira vez na vida, tive medo da violência. Meados dos anos 80. Guerrilhas, paramilitares, bombas, mortes e seqüestros faziam parte do prato dos colombianos, forçadamente habituados à violência desde tempos passados. Período duro. Perdi muitos amigos queridos que sonhavam e lutavam por um mundo melhor, de paz.

Voltei para o Brasil, acreditando que aqui viveria mais tranqüila. Mas aos poucos percebi que a violência da qual havia "fugido", avassaladoramente instalava-se na cidade de São Paulo. Concomitantemente retornei aos estudos da comunicação fazendo interface com o urbanismo. Na época, fui iniciada por uns amigos mais velhos ${ }^{3}$ em outros discursos relacionados à existência concreta da vida. O processo de envelhecimento e longevidade sensibilizou-me a ponto de atuar, hoje, como docente na área da Gerontologia 4 . Qual não foi a minha surpresa ao ver o cruzamento da violência com o envelhecimento ganhar cada vez mais destaque na mídia nacional como parte de um discurso político, sustentado especialmente pela Organização Mundial da Saúde.

Em uma investigação preliminar ${ }^{5}$ observamos que alguns programas (Datena-Band, Ratinho-SBT) exploram a imagem sensacionalista de algumas formas da velhice, absolutizam a miséria humana, mais uma mercadoria que tem como único objetivo segurar o ibope. Repetem imagens sensacionalistas de velhos, reduzindo a questão da velhice ao abandono, desrespeito e violência, principalmente por parte da família, do Estado e da sociedade. $\mathrm{Na}$ sua busca frenética pela "verdade", "deformam" "a realidade", tratando os idosos caricata e desrespeitosamente. Em tom invariavelmente 
sensacionalista, mostram uma das muitas faces do envelhecimento e da violência.

Outros, como a novela "Mulheres Apaixonadas", de autoria de Manoel Carlos, exibida pela rede Globo em 2003, mostraram ao Brasil como os idosos podem ser maltratados mesmo sob o teto de famílias de classe média e pelos próprios familiares. A violência doméstica resulta de um modelo cultural em que a estética é supervalorizada, em detrimento da velhice. Outra novela, "Belíssima", de autoria de Sílvio de Abreu, 2006, também exibida pela rede Globo: um dos papéis ocupados por alguns idosos era justamente o inverso: 0 velho como agente da violência contra o jovem (avó contra neta).

A mídia também mostrou o idoso refém de asilos genocidas (caso da Clínica Santa Genoveva, no Rio de Janeiro), abandonados pelas famílias, expulsos do paraíso prometido pela ciência e pelo consumo. A mesma mídia que omite a divulgação das causas da fragilização do sistema público de previdência...

Na mídia em geral os velhos aparecem mais porque são vítimas da violência. No início da década, o Brasil tratava o velho com indiferença, e só com a sua descoberta como um potencial consumidor é que ganhou importância social. Os velhos passaram a ser mostrados em anúncios de produtos farmacêuticos, higiene, cosméticos, alimentos, bancos, automóveis, aparelhos de telecomunicações. Normalmente são figurantes e não personagens principais, mas sempre carregam a imagem negativada da velhice, e quase sempre associada à doença. Até recentemente, a imagem do idoso na mídia era de alguém desatualizado intelectualmente e com dificuldade de aprender coisas novas. Por isso mesmo, os idosos não aparecem como fonte para os meios de comunicação, porque a própria palavra "idoso" ou "velho" carrega em si uma violência.

A palavra "idoso", como representação social - sistemas de interpretação que regem nossa relação com o mundo e com os outros, que orientam e organizam as condutas e as comunicações sociais (JODELET, 2001) -, aplica-se a um tipo de indivíduo e a um segmento social por ela representada. Segundo Gomes (2006), o termo idoso, de idadoso, ou pleno de idade, foi aplicado, em adequação a tempos e lugares, a diferentes faixas etárias. Esclarece que todas as aplicações tiveram como critério determinada 
média populacional de vida. O Estatuto do Idoso, sancionado pela presidência em setembro de 2003 depois de sete anos tramitando pelo Congresso, dispõe no Art. 10 "regular os direitos assegurados às pessoas com idade igual ou superior a 60 (sessenta) anos". Somos confrontados com uma resolução bastante clara: será considerado idoso aquele com idade igual ou superior a 60 anos! O isolamento de campo é bem preciso... e sob a determinação de um decreto. Vale lembrar que toda e qualquer cultura sofre mudanças, modifica-se no correr do tempo.

Portanto, à violência da palavra "idoso" ou "velho" se somou uma outra, a violência da generalização de um modelo social de velho altamente medicalizado, construído em oposição ao de jovem (MERCADANTE, 2003). A velhice também está sujeita a outras nomeações cujos significados são dados sempre pela cultura. Atualmente, as classificações clamam por uma consciência de categoria, de pertencimento a um campo de isolamento, como a palavra "aposentado" e "terceira idade", mas sempre como um novo dispositivo de controle político e social.

Para Mercadante (2004), há representação de identidade genérica do velho, que, pelo fato mesmo de ser geral, torna-se abstrata. $O$ velho é aquilo que "todo mundo já sabe", e todos o entendem como ser declinante biológica e socialmente. Todas as características a ele atribuídas, na construção da sua identidade, levam para essa representação social, para um modelo geral, predominantemente carregado de desígnios negativos. Contudo, a autora assinala que ao refletir sobre questões relativas ao idoso, descobriu, por meio de pesquisas realizadas desde meados da década de 1990 pelo Programa de Estudos Pós-Graduados em Gerontologia da PUC-SP, que existem diversos velhos e diferentes possibilidades de viver a velhice: "A velhice não é uma situação homogênea e os velhos não são iguais".

Os idosos (acima dos 60 anos) chegarão a 2 bilhões de pessoas, indica o relatório "Previsões sobre a População Mundial 2006", do Departamento de Assuntos Econômicos e Sociais das Nações Unidas ${ }^{6}$. Segundo o documento, as pessoas com mais de 60 anos representarão $32 \%$ da população mundial em 2050, e superarão pela primeira vez na história o número de crianças. Ou seja, os idosos representarão cerca de um quarto da população mundial projetada 
para 2050. Nos países em desenvolvimento a faixa etária de 60 anos ou mais deverá duplicar, passando de 245 milhões (2005) para 406 milhões em 2050.

Segundo estimativas do Instituto Brasileiro de Geografia e Estatística (IBGE), o Brasil terá mais de 260 milhões de habitantes em 2050, com idade média de 40 anos. Cerca de 14 milhões, no entanto, já terão ultrapassado a barreira dos 80 anos, pouco mais de $5 \%$ do total. Entre eles, as mulheres, por terem maior expectativa de vida, provavelmente serão maioria. Trata-se da feminização do envelhecimento. Hoje representam o maior número de pessoas com mais de 60 anos.

O prolongamento da vida exige redefinição das relações sociais, intergeracionais, na estrutura e funcionamento da metrópole de São Paulo, nas formas de produção, prestação de serviços, relações de consumo. Do contrário, triplicarão as diversas motivações que levam a atos violentos e às distintas tipologias de violências cometidas contra e por eles mesmos.

\section{Violência e velhice em monitoramento}

Nos últimos anos, a violência passou a fazer parte dos estudos sobre a velhice perpassando a mídia, que passa a representá-la, na maioria das vezes, a partir de eventos violentos extraordinários e pontuais, mostrando-nos que 0 envelhecimento é, hoje, estrutural e estruturante da sociedade. Daí a abordagem da mídia impressa, tentando analisar os discursos, tarefa nada fácil e muito árdua.

O envelhecimento tem sido tratado como problema que necessita de solução, seja assegurando direitos via Estatuto do Idoso, nas organizações do segmento idoso, e até pela própria violência - como resposta alarmante ao modelo da sociedade contemporânea ou como solução de um mal que deve ser expurgado. De qualquer maneira, o envelhecimento, da forma em que é relatado jornalisticamente, está sempre reduzido a uma faixa etária.

Só foi possível construir este texto a partir de informações extraídas de 209 matérias sobre velhice e violência, em 736 edições de quatro jornais impressos que circulam na metrópole - O Estado de S.Paulo (OESP) e o Jornal da Tarde (JT), do grupo Estadão; Folha de S.Paulo (FSP) e Valor Econômico (VE) do grupo Folha -, durante seis meses não consecutivos 
(junho, julho e agosto) em 2004 e 2005. Um texto, qualquer texto, não pode ser isoladamente interpretado.

Número de recortes totais por jornal relacionados a envelhecimento e violência

\begin{tabular}{|l|c|l|l|l|l|l|}
\hline Jornal & \multicolumn{2}{|l|}{2004} & \multicolumn{2}{l|}{2005} & \multicolumn{2}{l|}{ Total por jornal } \\
\hline & & violência & & violência & & violência \\
\hline O Estado de S.Paulo & 463 & 27 & 407 & 19 & 870 & 46 \\
\hline Jornal da Tarde & 362 & 57 & 273 & 55 & 635 & 112 \\
\hline Folha de S.Paulo & 99 & 13 & 243 & 32 & 342 & 45 \\
\hline Valor Econômico & 70 & 01 & 59 & 5 & 129 & 6 \\
\hline TOTAL por recortes & 994 & 98 & $986^{*}$ & 111 & $1980^{*}$ & 209 \\
\hline
\end{tabular}

* Desse total, quatro jornais não foram identificados, e estão dentro da margem de erro.

Elementos de ordem social que o nortearam e o contexto no qual foi escrito certamente remeterão o leitor a dúvidas, inquietações e olhares distintos dos pretendidos por quem o escreveu. Nada diferente ocorre quando os temas são a velhice e a violência a ela relacionada: as notícias não podem ser dissociadas dos diversos discursos - biológicos, culturais e teóricos - que fundamentam essa importante etapa da vida.

Os textos analisados geralmente anunciam e enunciam a velhice e a violência de forma excepcional, anormal ou de grande impacto social, como acidentes, assassinatos, seqüestro. Dos meses pesquisados, julho foi o que mais apresentou textos relacionados à temática. No entanto, manteve-se a média de recortes sobre o envelhecimento e a violência nos dois anos de pesquisa. $E$ entre os jornais analisados, o JT deu maior cobertura à violência, o que também pode ser explicado ser um veículo de comunicação local e, portanto, cobrir aspectos mais particulares da metrópole. O jornal VE foi o que menos apresentou matérias relacionadas à violência, o que se justifica por sua especificidade.

Os textos encontrados no conteúdo das notícias, no título e na imagem na editoria, assim como no conteúdo do subtítulo na editoria, foram os 
principais motivos que levaram ao recorte das mesmas. Mas, com um levantamento detalhado, observamos algumas diferenças entre os jornais analisados. Para o JT, o principal motivo é o conteúdo da matéria, seguido do conteúdo do subtítulo, frases de destaque e imagem na editoria. Para a FSP, é o título na editoria, seguido do conteúdo da notícia e imagem na editoria. No jornal OESP, o conteúdo da matéria foi o que levou ao recorte da notícia, seguido do título da editoria e inter-relação do título com o tema da velhice e violência.

Os textos selecionados estavam localizados principalmente nas editorias Polícia/Segurança, Internacional/Mundo, Cidade e Cotidiano. Ou seja: cada jornal tem uma política diferenciada na cobertura da violência e velhice. O JT a entende como caso de polícia, pois é coberta pela editoria de Polícia/Segurança. Apresentou grande número de recortes alocados nesse espaço. Nos demais jornais, o número de recortes na editoria é irrelevante em relação ao total. Para o jornal OESP, a violência e a velhice não fazem parte da pauta diária. O maior número de recortes foi extraído da editoria Caderno/Encarte/Suplemento/Estadão Sul. A FSP a trata na editoria Cotidiano, enquanto o VE a entende como assunto da editoria Economia/Finanças. Exceto no VE, Internacional/Mundo destaca-se como a segunda editoria, em números absolutos, na cobertura dos temas velhice e violência. As matérias publicadas em Internacional/Mundo chegam às redações a partir de agências internacionais de notícias.

Número de recortes por jornal segundo as editorias dos mesmos

\begin{tabular}{|l|c|c|c|c|c|}
\hline \multicolumn{1}{|c|}{ Editorias } & \multicolumn{4}{c|}{ Jornal } & Total \\
\cline { 1 - 5 } & $\begin{array}{c}\text { O } \\
\text { Estado } \\
\text { de } \\
\text { S.Paulo }\end{array}$ & $\begin{array}{c}\text { Folha } \\
\text { de } \\
\text { S.Paulo }\end{array}$ & $\begin{array}{c}\text { Jornal } \\
\text { da } \\
\text { Tarde }\end{array}$ & $\begin{array}{c}\text { Valor } \\
\text { Econômico }\end{array}$ & \\
\hline Polícia/Segurança & 2 & 3 & 55 & & 60 \\
\hline Economia/Finanças & 1 & 2 & 1 & 5 & 8 \\
\hline $\begin{array}{l}\text { Caderno/Encarte/Suplemento/Estadão } \\
\text { Sul }\end{array}$ & 1 & 2 & 3 & & 6 \\
\hline
\end{tabular}




\begin{tabular}{|l|c|c|c|c|c|}
\hline Cidade & 24 & & 14 & & 38 \\
\hline Esporte & & & 2 & & 2 \\
\hline Internacional/Mundo & 10 & 13 & 28 & & 51 \\
\hline Opinião/Espaço Aberto & & & 2 & & 2 \\
\hline Política & 1 & & 1 & 1 & 3 \\
\hline Variedades/Roteiro & 4 & 3 & 1 & & 8 \\
\hline Sua Vida & 2 & & & & 2 \\
\hline Cotidiano & & 22 & & & 22 \\
\hline Total & 44 & 45 & 107 & 6 & $202^{*}$ \\
\hline
\end{tabular}

* Em sete recortes não se especificou em qual editoria se encontrava a notícia

A violência ocorreu predominantemente no espaço público, coberto com mais intensidade pela FSP. Mas, ao se analisar separadamente cada jornal, verifica-se que no JT o espaço privado mereceu maior destaque. A constatação corrobora a função desse periódico: divulgar com maior intensidade o ambiente doméstico.

Nos quatro jornais analisados a maior parte das notícias recortadas teve como procedência textos de agências locais. A cidade de São Paulo foi quem mais produziu informações. A cidade do Rio de Janeiro aparece em segundo lugar, fornecendo um número muito pequeno de informações para os quatro jornais analisados. O JT apresentou o maior número de imagens, seguido da FSP e OESP.

Quanto à angulação, observou-se que a maior parte das matérias se manteve neutra, embora algumas mostrassem uma velhice positivada (idosos envolvidos em projetos e com acesso ao mercado de trabalho e lazer). Houve também a imagem negativada da velhice (preconceitos e inatividade). Em alguns textos recortados observamos a presença de adjetivações, algumas inclusive com palavras popularescas.

A maioria dos personagens das notícias são pessoas comuns. Certamente por isso raramente convidadas a opinar sobre os acontecimentos, preferência que invariavelmente se fixava nas chamadas "fontes oficiais". Os idosos e idosas pouca atenção mereceram de quem tem a obrigação, 
profissional e moral, de reportar os fatos, ouvindo, sempre que possível (e isso normalmente é sempre possível), todos os lados envolvidos.

A falha (proposital?) torna-se ainda mais imperdoável se forem elencadas entidades e instituições cuja existência fundamenta-se na organização e proteção aos idosos: Conselhos Nacionais e Locais de Direitos dos Idosos, SOS-Idoso; Ligue-Idoso, Promotoria do Idoso e muitos outros, além de dispositivos legais e normativos existentes para o enfrentamento da violência. Assim como há abissal distância entre leis, portarias e sua implantação, é absurda a separação entre a mídia impressa e a sociedade quanto às fontes de informação, o que implica, como tudo que envolve a velhice, mudanças dos processos de comunicação, usos e costumes redacionais ${ }^{7}$, das mentalidades a respeito do envelhecimento, enfim, do ideário da velhice.

A velhice, diferentemente de estado de carência ou perda, é movimento que permite ao ser humano aceder à plenitude de uma relação acabada consigo mesmo (Tótora, 2005). Concordamos com Foucault (2004), ao assinalar que "a velhice não é apenas uma fase cronológica da vida: é uma forma ética que se caracteriza ao mesmo tempo pela independência relativamente a tudo que não depende de nós, e pela plenitude de uma relação consigo em que a soberania não se exerce como combate, mas como gozo".

Os idosos hoje reescrevem a si mesmos. São produtores culturais. Por isso, são imprescindíveis na elaboração, pelos profissionais da imprensa, de textos diferenciados - passando de coadjuvantes a atores principais, quando se trata de fontes de informação. Afinal, vivem, experimentam - como geração - prolongada vida adulta, marcada pela coexistência de identidades múltiplas e multiplicidade de papéis. Afinal, dar-Ihes a palavra e interrogar os valores, normas e conceitos/preconceitos com os quais são geridos o envelhecimento e as idades pode orientar uma nova cultura sobre a longevidade (Quaresma, 2006).

Mas não basta incorporar os idosos como fonte de informação se o seu espaço não tiver o mesmo destaque dado às demais fontes. As lições aprendidas no jornalismo ressaltam que todo repórter deve ouvir todos os lados de um fato para a reportagem ser objetiva. Diariamente observa-se, porém, que de acordo como os depoimentos são colocados nos textos, esvai-se a 
objetividade tão intensamente perseguida pelo jornalismo. Quando se decide por uma fonte, especialmente aquela que abre a matéria (e/ou a citada no título, lead, olho ou subtítulo), prioriza-se o valor do seu depoimento. Inegavelmente. $\mathrm{Na}$ cobertura da violência, as fontes oficiais aparecem com destaque. Infelizmente, na cobertura da velhice e violência evidenciou-se, nesta pesquisa, que se produz um tipo de jornalismo intitulado pejorativa e ironicamente de jornalismo "chapa-branca". As fontes oficiais, os especialistas e a elite recebem atenção primordial dos responsáveis pela apuração dos fatos e pela divulgação das informações. Isso obriga a repensar a desqualificação sistemática da maioria da população, especialmente do segmento idoso, tanto como fonte de informação quanto como composição demográfica crescente. Afinal, para quem os jornais continuarão editando suas publicações?

Atualmente, a população tem recorrido mais à mídia para denunciar diversas formas de violência. Ouvir os grupos organizados de idosos, opiniões a respeito, além de contextualizar as notícias, certamente os incluiria na busca de solução para a violência que os envolve.

O discurso de informação abordado nos textos recortados exerce a função de ponto de referência para quem os lê. A narrativa apresentada aos leitores por meio dos diversos crimes, como vítimas ou agentes, tem importância significativa na construção dos discursos sobre a velhice. A partir dos recortes construímos outro texto. A exemplo do anterior, define também como os leitores devem pensar a violência contra o idoso e este como agente do crime, permeando, todo o tempo, um ideário sobre a própria velhice.

Partiu-se de duas perguntas: 1) O discurso que a própria violência contra o idoso foi criando para si por meio das narrativas dos jornais revela a representação de uma identidade genérica de velho (ser declinante, biológica e socialmente). Por isso ele deve ser descartado em função de uma cultura jovem, transformada em bem, em valor? 2) É possível que a produção jornalística faça algum "desenho" da velhice que não seja contaminado por estereótipos que veiculam visão preconceituosa?

A pesquisa em si responde às questões. Na cobertura da violência não se detectou nenhuma representação da velhice que não estivesse contaminada pelos estigmas. Também não se identificou uma visão demasiadamente 
preconceituosa, como se imaginava, exceto quando o idoso era agente do crime.

Esta pesquisa mostrou quais são os crimes que mais aparecem na mídia. Nas primeiras páginas dos jornais analisados, os crimes mais representados estão relacionados a: 1) preconceito: envolvendo especialmente atrizes globais; 2) crime ambiental: cometido por apresentador de TV; 3) roubos: especialmente a casas e apartamentos de pessoas de classe média e bancos; 4) assassinato: muitos seguidos de roubo, mas quase todos envolvendo empresários; 5) seqüestro: especialmente mulheres idosas, por relação econômica ou política da vítima com membros da família; 6) suicídio e 7) atropelamentos: envolvendo pessoas comuns, como vítimas e agentes.

Nas editorias, a ordem se altera.

Como vítimas, mais aparecem os crimes que colocam em risco a vida das pessoas: assassinato, seqüestro, roubo, atropelamento, crime sexual. Em relação aos crimes em geral, os homens, em maior número, agridem e são agredidos - autores e vítimas. A mídia, entretanto, destacou com maior evidência as vítimas femininas, passando a falsa impressão ao leitor que o seqüestro, por exemplo, é maior em relação às mulheres. Em roubos, há predominância masculina. Somente nos crimes sexuais a maioria das vítimas é do sexo feminino. Os agressores são homens, de 26 a 48 anos. Em dois casos as vítimas os conheciam. Também em assassinato intrafamiliar, as vítimas são mulheres e os agressores, homens com estreito grau de parentesco. Em muitas notícias não há informações sobre os agressores, mas é interessante notar que a maioria das vítimas de assassinatos está acima de 75 anos, o mesmo acontecendo em relação aos seqüestros. Quanto aos seqüestradores não há informação precisa. Mas a partir dos casos cobertos, quadrilhas são a maioria: ao menos mais de uma pessoa está envolvida, com alguém conhecido da família. Nos atropelamentos, não é possível classificar o agente principal pela cobertura analisada: houve adolescentes, jovens, homens e mulheres, na faixa de 16 a 58 anos. As vítimas são de ambos os sexos, com predominância do sexo feminino.

Em todas as notícias, não é freqüente a adjetivação dos idosos no jornalismo impresso. O índice de notícias de homicídio é alto, e a polícia é a fonte de notícias mais utilizada. A maioria das vítimas é do sexo masculino, na 
faixa dos 65 anos. Octogenários também apareceram como vítimas, um com 94 anos. Pouco se publica sobre os agressores ou a penalidade.

Em relação aos crimes que afetam a integridade física, moral, mental ou espiritual, receberam maior cobertura os que incluem constrangimento, envolvendo homens e mulheres, instituições públicas e privadas. Em seguida, repercussão da violência urbana, que também envolveu homens e mulheres; e estelionato/apropriação indébita e outras violências não decorrentes de crime, envolvendo idosos em geral, sendo os agressores homens, mulheres e "instituições".

Em relação aos idosos como agentes do crime, os principais crimes publicados nos jornais foram assassinato, roubo, crime de guerra, atropelamento, crime sexual, drogas e suicídio. São crimes nos quais os idosos colocavam em risco a vida de cidadãos. A maioria dos agressores também são homens, e os crimes ocorreram antes de completarem 60 anos. Assim se passou com os crimes de guerra (todos os recortes relacionavam-se a notícias internacionais). No item "assassinato", a cobertura maior refere-se a crimes ocorridos fora do país. As mulheres são as principais vítimas, em seguida crianças e jovens, e os agressores, homens. Em roubos, a grande parte das notícias tratou da cobertura internacional, quase todas relacionadas a bancos.

Nesse tipo de cobertura, em praticamente todos os casos analisados, a notícia é acompanhada do relato do que ocorreu após o crime, até mesmo sendo citada a pena, o que freqüentemente não ocorre com as notícias nacionais. $O$ fato explica-se porque a notícia internacional chega à redação via agências, transcorridos dias, ou meses, do fato. Isso permite que haja, no corpo da notícia, o fato e o seu andamento, a sua repercussão. Há ainda as notícias que já informam a sentença. É freqüente observar a impunidade, relatada nas notícias nacionais. A justificativa recai sobre a morosidade do sistema penal, ou a cobertura não se preocupa em acompanhar o caso.

No item "roubos" estão os termos pejorativos mais freqüentes: "velhinha", "gangue dos vovôs", "vovó". Expressões que indicam um tipo de representação social existente dos velhos: não fazem mal, são "bonzinhos". Quando cometem algum crime logo são tachados pejorativamente. O que não ocorre quando o idoso é vítima. Exemplo: em nenhum momento a imprensa ironizou dona Vitória, a senhora de 80 anos que, desacreditada por policiais 
após denunciar o tráfico que ocorria em frente ao seu prédio, no Rio de Janeiro, resolveu filmar tudo e denunciar à imprensa. Foi descrita em uma das matérias como pessoa que exerceu a sua cidadania.

A maioria dos idosos criminosos sempre viveu no crime. Portanto, no processo de envelhecimento a tendência é de nele permanecer, em decorrência da ineficiência do sistema de ressocialização. Quanto aos atropelamentos, as sete notícias selecionadas tratam de apenas dois casos: 0 primeiro cometido por homem, o segundo por mulher. Crianças, jovens e adultos foram vítimas, recebendo duas chamadas de primeira página. Essa cobertura também transmitiu ao leitor a percepção de estar aumentando o número de atropelamentos ocasionados por idosos. Um deles foi acidental, mas a mídia o relacionou à deficiência e à velhice, dois grandes estigmas sociais.

Em relação aos crimes sexuais, os agressores são homens e as vítimas, crianças e jovens de ambos os sexos. No que se refere às drogas, identificaram-se duas notícias nas quais fica explícita a entrada da pessoa idosa no crime, homem e mulher, os dois sexos sem antecedentes criminais. Embora pesquisas tenham enfatizado que as taxas de suicídio, no Brasil, elevaram-se em 200\%, nos dois anos apenas um suicídio foi noticiado, praticado por um homem.

Dispersas foram as notícias sobre os crimes cometidos por idosos e que afetam a integridade física, moral, mental ou ambiental de outras pessoas, idosas e não idosas. No item "corrupção", encontram-se crimes relacionados a homens públicos. Em "pensão", homens e mulheres estão envolvidos. Em "preconceito" e "crime ambiental", houve a cobertura porque os agentes do crime eram pessoas públicas, presentes na mídia televisiva. Em "estelionato", o crime citado é inusitado e mostra como também a Justiça estrangeira pode constranger a pessoa idosa. Finalmente, no quesito "outros" estão envolvidos homens e mulheres.

Em geral, pode-se afirmar que entre os crimes cobertos pela mídia impressa de São Paulo, a maioria dos agentes compõe-se de homens, que também são as maiores vítimas, exceto os intrafamiliares. Uma das hipóteses é porque a maioria dos crimes ocorre em espaços públicos, onde os homens tradicionalmente mais estão presentes. 
A pesquisa mostra que os velhos aparecem na mídia impressa, como vítimas e agentes, em igual proporção, diferentemente do que se imaginava no início da pesquisa.

Ou seja: não são invisíveis. A constatação pode ser explicada por dois motivos: primeiramente, por ser o segmento da população que mais cresce. Portanto, tornam-se segmentos importantes de leitores de jornais, que não pode mais ser ignorado pelos proprietários e editores dos jornais analisados. Em segundo lugar, gradativamente se fazem ver, se "mostram", ganham visibilidade. Deixam o espaço privado e ocupam o espaço público.

O cenário seria outro se nas manchetes e textos as fontes principais fossem os idosos "comuns". Daí a necessidade de os profissionais da mídia saberem um pouco mais a seu respeito, do mesmo modo como a imprensa se viu obrigada a conhecer, detalhadamente, problemas e anseios de crianças e adolescentes - assim como saber tratar o assunto, até mesmo para não se tornarem objeto de ações judiciais.

$\mathrm{Na}$ cobertura relacionada à violência houve, implicitamente, a valorização da juventude, especialmente nos casos em que idosas foram assassinadas por parentes, seqüestradas, roubadas ou abusadas sexualmente.

Nos crimes nos quais os velhos estão envolvidos, os ricos são as principais vítimas, diferentemente dos jovens, em que os pobres lideram esse triste ranking. Os privilegiados economicamente, que sempre encontraram fórmulas privadas de proteção, estão desprotegidos. Mesmo encerrados em espaços privados, são alvo de violências que assumem, diariamente, formas diferenciadas, complexas e assustadoras - realidade que não se restringe ao Brasil.

Os velhos se tornam alvo fácil por estarem mais vulneráveis, hipótese que surge a partir dos temores em relação às fragilidades humanas que todos apresentaremos quando do próprio envelhecimento.

Pensar a cultura da violência e da velhice é, de certo modo, interferir no continuum da vida. Repensar a velhice e a violência contemporânea exige da produção jornalística, e dos leitores, encontrar outros textos, recriando-se novos ideários permanentemente, o que pressupõe lidar com o que há de mutabilidade, relatividade e imprevisibilidade no ser que envelhece. Somente 
assim será possível construir velhices não estereotipadas. Algumas propagandas têm contribuído para mudar a imagem da velhice, com idosos independentes, felizes, em atividades jamais vistas (Ribeiro, 2007). São seres desejantes, desejados, não decrépitos. De certa maneira, a propaganda embora vista por alguns estudiosos apenas como ferramenta do consumo -, como informação tem sido o meio mais eficiente, convincente e rápido de ressaltar possibilidades de se vivenciar velhices distintas das presentes em nosso imaginário. Rompe-se com a violência da generalização. O Plano de Ação Internacional sobre o Envelhecimento, decidido na Assembléia de Madri, em 2002, evidenciou que os meios de comunicação devem contribuir com imagens positivas a respeito do envelhecimento.

Há outros pontos a serem destacados: vive-se cada vez mais em boas condições físicas e mentais, e a realidade demográfica indica uma sociedade, em futuro não tão distante, na qual os velhos serão a maioria. Há de se pressupor, portanto, que os velhos serão os principais consumidores de toda sorte de produtos, incluindo os informativos.

A mídia pode orientar os comportamentos? Os meios de comunicação exercem papel relevante na sociedade, ajudam a entender (ou não) a realidade do lugar em que se vive, mesmo fragmentado, amplificado, simplificado e estereotipado. Portanto, é capaz de orientar comportamentos para um ideário de velhices que não as representadas.

Ainda que a cobertura casual e sem compromisso da produção jornalística tenha revelado mais a violência do que a velhice, os textos encontrados foram menos negativos do que a autora supunha ao iniciar o trabalho. Observação otimista: não se reforçou o preconceito existente. Credita-se o fato certamente à formação dos profissionais, regidos, teoricamente, por normas de neutralidade.

Mas mesmo perseguindo as ditas objetividade e neutralidade, o cenário se transformaria se notícias negativas fossem substituídas por informações que transmitissem uma imagem mais coerente daquela que vivem os velhos, não só como vítimas ou delinqüentes. 


\section{Referências Bibliográficas}

CÔRTE, B.; IARCURI, I. e MERCADANTE, E. Envelhecimento e velhice: um guia para a vida. São Paulo: Vetor, 2006.

FOUCAULT, M. A hermenêutica do sujeito. São Paulo: Martins Fontes, 2004.

GOMES, M. R. Poder no Jornalismo. São Paulo: Edusp, 2003.

GOMES, M. R. "O Estatuto do Idoso e as identificações". In: CÔRTE, B. ARCURI, I. E MERCADANTE, E. (orgs.). Envelhecimento e velhice: um guia para a vida. São Paulo: Vetor, 2006.

JODELET, D. (org.). As representações sociais. Rio de Janeiro: Uerj, 2001.

MERCADANTE, E.F. "Velhice: a identidade estigmatizada". Revista Serviço Social e Sociedade, 75, ano XXIV. Especial Velhice e Envelhecimento. São Paulo: Cortez, 2003.

MERCADANTE, E. F. "Do geral para o particular". Revista Kairós, vol. 7, nº 1. São Paulo: Educ, 2004.

QUARESMA, M.L. Gerontologia e Gerontologia Social: contributos para a análise de um percurso. Revista Kairós-Gerontologia, vol. 9, $n^{0}$ 1. São Paulo: Educ, 2006.

RIBEIRO, R.N. A construção da velhice positivada em propagandas direcionadas a público idoso [Dissertação de mestrado - Programa de Estudos Pós-Graduados em Psicologia Social]. São Paulo: PUC-SP, 2007. TÓTORA, S. I Conferência Nacional de Direitos do Idoso. Brasília, DF, 15/8/2005. Disponível em:

http://www.portaldoenvelhecimento.net/artigos/artigo546.htm\# ftnref8\# ftnref8

\footnotetext{
1 Os dados aqui apresentados fazem parte de pesquisa de pós-doutorado realizada na Escola de Comunicações e Artes da Universidade de São Paulo (2007), supervisionada pela Profa. Dra. Mayra Rodrigues Gomes, docente da ECA/USP.

${ }^{2}$ Professora do Programa de Estudos Pós-Graduados em Gerontologia da Pontifícia Universidade Católica de São Paulo (PUC-SP). Coordenadora executiva do website Portal do Envelhecimento. Líder do Grupo de Pesquisa: Longevidade, Envelhecimento e Comunicação (LEC), e pesquisadora do Núcleo de Estudo e Pesquisa do Envelhecimento (NEPE), ambos certificados pelo CNPq. Editora da revista KairósGerontologia. E-mail: beltrina@uol.com.br

${ }^{3}$ Principalmente por Tomiko Born, que durante muitos encontros regados a vinho no quintal de sua casa discutia-se - junto com seus outros amigos - os desafios do ser que envelhece, especialmente seus modos de morar.

${ }^{4}$ Área do conhecimento relativamente jovem, dos anos 40, que estuda o processo de envelhecimento; diferente da geriatria, que estuda suas patologias.
} 


\footnotetext{
${ }^{5}$ Apresentada ao Núcleo de Pesquisa Comunicação para a Cidadania, no XXIX Congresso Brasileiro de Ciências da Comunicação, em 2006, em co-autoria com Mayra Rodrigues Gomes.

${ }^{6} \mathrm{Cf}$. o texto População idosa será maior que a de crianças pela $1^{a}$ vez na história em 2050, disponível em http://noticias.uol.com.br/ultnot/efe/2007/04/11/ult1766u21157.jhtm, acessado no dia 11/04/2007.

${ }^{7}$ Um deles poderia ser o hábito dos profissionais da mídia pesquisarem via on-line as bibliotecas, a fim de consultar o que é produzindo sobre o envelhecimento. Evitariam a repetição de discursos obsoletos e preconceituosos.
} 